\title{
A Brief Measure of Narcissism Among Female Juvenile Delinquents and Community Youths: The Narcissistic Personality Inventory-13
}

International Journal of Offender Therapy and Comparative Criminology 20I8, Vol. 62(8) 2292-23II

(C) The Author(s) 2017

Reprints and permissions: sagepub.com/journalsPermissions.nav DOI: $10.1177 / 0306624 \times 17700855$ journals.sagepub.com/home/ijo

(SAGE

\section{Pedro Pechorro',2, João Maroco ${ }^{3}$, James V. Ray4, Rui Abrunhosa Gonçalves', and Cristina Nunes ${ }^{5}$}

\begin{abstract}
Research on narcissism has a long tradition, but there is limited knowledge regarding its application among female youth, especially for forensic samples of incarcerated female youth. Drawing on 377 female adolescents (103 selected from forensic settings and 274 selected from school settings) from Portugal, the current study is the first to examine simultaneously the psychometric properties of a brief version of the Narcissistic Personality Inventory (NPI-13) among females drawn from incarcerated and community settings. The results support the three-factor structure model of narcissism after the removal of one item due to its low factor loading. Internal consistency, convergent validity, and discriminant validity showed promising results. In terms of criterion-related validity, significant associations were found with criterion-related variables such as age of criminal onset, conduct disorder, crime severity, violent crimes, and alcohol and drug use. The findings provide support for use of the NPI-I 3 among female juveniles.
\end{abstract}

\section{Keywords}

assessment, Narcissistic Personality Inventory-13, incarcerated female juvenile delinquents; validation

\footnotetext{
'University of Minho, Braga, Portugal

2University of Coimbra, Portugal

${ }^{3}$ ISPA-Instituto Universitário, Lisbon, Portugal

${ }^{4}$ University of Central Florida, Orlando, USA

${ }^{5}$ Centre for Spatial and Organizational Dynamics, University of Algarve, Portugal

Corresponding Author:

Pedro Pechorro, School of Psychology, University of Minho, Campus de Gualtar, 47I0-057 Braga,

Portugal.

Email:ppechorro@gmail.com
} 
Narcissism is a multidimensional construct that has a long tradition in the psychoanalytic and clinical literatures. According to the Diagnostic and Statistical Manual of Mental Disorders (5th ed.; DSM-5; American Psychiatric Association [APA], 2013), the central characteristics of narcissism include a grandiose sense of self-importance, a need for the admiration of others, arrogance, a sense of uniqueness and entitlement, a lack of empathy, envy, and a tendency to exploit others.

Narcissistic Personality Disorder (NPD) is one of the least common personality disorders, and the estimates of its prevalence vary quite widely. Some researchers indicate that NPD affects from $0 \%$ to $1 \%$ of the general population (Samuels et al., 2002; Torgerson, Kringlen, \& Cramer, 2001) although others have found rates of 3.9\% to $5.3 \%$ in nonclinical control samples (Bodlund, Ekselius, \& Lindström, 1993; Klein et al., 1995). However, in an epidemiologic survey in the United States, prevalence of lifetime NPD was 6.2\% (Stinson et al., 2008). NPD was associated with mental disability among men but not women. High co-occurrence rates of substance use, mood, anxiety, and other personality disorders were observed (Stinson et al., 2008).

NPD is more frequently found among people with higher education or special professional groups (Maffei et al., 1995), more common in males (Foster, Campbell, \& Twenge, 2003; Robins \& Trzesniewski, 2005; Stinson et al., 2008), and more prevalent in clinical settings (Shedler \& Westen, 2007). There is also evidence for agerelated differences, suggesting that narcissism may dissipate across the life course (Foster et al., 2003; Wilson \& Sibley, 2011).

Empirical evidence suggests that narcissism may be a core feature underlying antisocial behavior among youth. Research has consistently found an association between narcissism and antisocial behavior (e.g., Barry, Grafeman, Adler, \& Pickard, 2007; Chabrol, Van Leeuwen, Rodgers, \& Séjourne, 2009), behavioral problems, proactive aggression, and low self-esteem (e.g., Lau \& Marsee, 2013; Muñoz, Kimonis, Frick, \& Aucoin, 2013; Washburn, McMahon, King, Reinecke, \& Silver, 2004). In addition, research has found important associations between narcissism and psychopathic traits among youth (Andershed, Gustafson, Kerr, \& Stattin, 2002; Lynam, 2011). Barry, Frick, and Killian (2003) found positive correlations between maladaptive dimensions of narcissism (e.g., Exhibitionism, Exploitativeness, and Entitlement) and callousunemotional (CE) traits. In addition, Feilhauer, Cima, and Arntz (2012) suggested that items from the Inventory of Callous-Unemotional Traits (ICU; Kimonis et al., 2008) capturing a "lack of conscience" were positively related with maladaptive narcissism.

One of the measures most commonly used and well-validated for subclinical levels of narcissism is the Narcissistic Personality Inventory (NPI; Raskin \& Hall, 1979), which consisted of 80 items based on the Diagnostic and Statistical Manual of Mental Disorders (3rd ed.; DSM-III; APA, 1980) criteria for NPD. A shorter version, consisting of 40 forced-choice items, was introduced later (Raskin \& Terry, 1988). It measures narcissism as a continuous construct, in which extreme manifestations represent pathological narcissism and less extreme forms reflect narcissism as a personality trait (Emmons, 1987). There is no specific cutoff score for which a person would be considered a clinical narcissist (Foster \& Campbell, 2007). It has seven subscales: Authority (eight items), Self-Sufficiency (six items), Superiority (five items), 
Exhibitionism (seven items), Exploitativeness (five items), Vanity (three items), and Entitlement (six items).

The NPI correlates positively with high self-reported self-esteem (e.g., Emmons, 1984, 1987; Raskin \& Terry, 1988; Rhodewalt \& Morf, 1995), self-focused attention (Emmons, 1987), self-referencing (Raskin \& Shaw, 1988), need for uniqueness (Emmons, 1984), need for power (Carroll, 1987), and with lack of discrepancy between actual and ideal self (Rhodewalt \& Morf, 1995). The NPI was also found to be negatively associated with relationship-related variables - empathy and perspective taking (Watson, Grisham, Trotter, \& Biderman, 1984), agreeableness (Rhodewalt \& Morf, 1995, 1998), and need for intimacy (Carroll, 1987) — and to correlate positively with hostility (Bushman \& Baumeister, 1998; Rhodewalt \& Morf, 1995).

Although research has extensively validated the NPI (e.g., Calhoun, Glaser, Stefurak, \& Bradshaw, 2000; Emmons, 1984; Raskin \& Terry, 1988; Rhodewalt \& Morf, 1995), concern with regard to its construct validity exists largely due to modest reliabilities of its subscales, uncertain factor structure, and ambiguity about how to interpret the total score when it is summed across the items (e.g., R. P. Brown, Budzek, \& Tamborski, 2009). It is worth mentioning that the forced-choice format usually results in lowered reliability due to the way the forced-choice questionnaires have been scored traditionally (A. Brown \& Maydeu-Olivares, 2011, 2013). If the reduction in reliability is substantial, then it may not be possible to achieve adequate validity (Domino \& Domino, 2006).

In addition, the length of the NPI may prohibit its use in settings where time pressure and respondent fatigue are major concerns (Ames, Rose, \& Anderson, 2006).

To improve assessment efficiency, Gentile and colleagues (2013) developed a brief measure of narcissism, composed of 13 items with the following factors: Leadership/ Authority (LA; four items), Grandiose Exhibitionism (GE; five items), and Entitlement/ Exploitativeness (EE; four items).

The NPI-13 has shown good psychometric characteristics, namely, internal consistency, exceeding the recommended minimum Cronbach's alpha of .70, with the exception of the EE subscale (with an alpha of .52), and good criterion-related validity. In addition, NPI-13 showed good psychometric properties with a Portuguese male youth forensic sample, justifying its future use with similar samples (Pechorro, Gentile, Ray, Nunes, \& Gonçalves, 2016).

In short, narcissism is an underlying central characteristic of antisocial behavior among youth, and the NPI-13 is a relevant measure among samples of antisocial youth. However, the available research has some gaps to overcome. Additional research is necessary to adapt short measures of narcissism such as the NPI-13 to female juvenile offenders and culturally distinct samples (see Grijalva et al., 2015), while analyzing its forensic importance.

Although men have been overrepresented in aggression and criminal behavior (Cross, Copping, \& Campbell, 2011), an increase in deviant behavior is being increasingly registered in females, with female detainee rates augmenting steadily in the past decades (Cauffman, 2008; Chesney-Lind \& Shelden, 2014). Past research has found that boys and girls have significantly different levels of narcissism (Foster et al., 2003; 
Robins \& Trzesniewski, 2005; Stinson et al., 2008). However, as Grijalva and colleagues (2015) pointed out, more research is needed to examine the contextual, social, and biological aspects that contribute to gender differences in narcissism.

The main aim of the present study is to assess the psychometric properties of the Portuguese version of the NPI-13 among incarcerated female juvenile delinquents and community youths. It was hypothesized that (a) the factor structure of the NPI-13 proposed by Gentile et al. (2013) would be replicated among the current forensic sample using confirmatory factor analysis (CFA); (b) the NPI-13 would show convergent validity with existing measures of psychopathic traits and aggression, and discriminant validity with a social anxiety measure; and (c) the NPI-13 scores in terms of criterion-related validity would be significantly associated with conduct disorder (CD), age of crime onset, age of first problem with the law, increased crime severity, use of physical violence, alcohol abuse, and drug use.

\section{Method}

\section{Participants}

The sample was composed of 377 female participants $(N=377$; mean age $=16.23$ years; $S D=1.38$ years; range $=14-19$ years) recruited from forensic (i.e., juvenile detention facilities) and school contexts. Of this total, 103 participants $(n=103$; mean age $=16.41$ years; $S D=1.19$ years; range $=14-18$ years) formed the forensic sample and 274 participants $(n=274$; mean age $=16.17$ years; $S D=1.44$ years; range $=14-19$ years) formed the school sample. The participants were mainly White Europeans (forensic sample $=59.2 \%$; school sample $=90.1 \%$ ) from an urban background (forensic sample $=97.1 \%$; school sample $=100 \%$ ) with a low socioeconomic status (SES; forensic sample $=60.2 \%$; school sample $=39.1 \%$ ). The detained youths had their crime onset $(M=12.50$ years; $S D=1.56$ years $)$ and first criminal problems with the law $(M=13.27$ years; $S D=1.55$ years $)$ early in their lives. Most were detained before they were 16 years old $(M=15.90, S D=1.04)$ due to having committed serious and violent crimes (e.g., robbery, assault).

\section{Measures}

The Narcissistic Personality Inventory-13 (NPI-13; Gentile et al., 2013) is a short 13 forced-choice items version of the NPI (Raskin \& Terry, 1988), considered the most widely used measure of trait narcissism. Gentile et al. (2013) developed the NPI-13 specifically to maintain the three-factor structure derived by Ackerman et al. (2011): LA, GE, and EE. The three-factor structure of the NPI-13 was supported using CFA (Gentile et al., 2013). The Portuguese adaptation of the NPI-13 (Pechorro, Gentile, et al., 2016) was used.

The Antisocial Process Screening Device-Self-Report (APSD-SR; Caputo, Frick, \& Brodsky, 1999; Frick \& Hare, 2001) is a multidimensional 20-item measure designed to assess psychopathic traits in adolescents. It was modeled after the 
Psychopathy Checklist-Revised (PCL-R; Hare, 2003). The APSD has three main factors: Callous-Unemotional, Narcissism, and Impulsivity. Each item is scored on a 3 -point ordinal scale $(0=$ not at all true, $1=$ sometimes true, or $2=$ definitely true $)$. The total score, as well as each dimension score, is obtained by adding the respective items. Higher scores are indicative of an increased presence of psychopathic traits (Frick \& Hare, 2001). The Portuguese validation of the APSD-SR (Pechorro, Hidalgo, Nunes, \& Jiménez, 2016; Pechorro, Maroco, Poiares, \& Vieira, 2013) was used. The internal consistency for the current study, estimated by Cronbach's alpha, was .77.

The Youth Psychopathic Traits Inventory (YPI; Andershed et al., 2002) is a 50-item self-report measure designed to assess the core personality traits of the psychopathic personality constellation in youth aged 12 years and above. Each item is scored on an ordinal 4-point ordinal scale (ranging from $1=$ does not apply at all to $3=$ applies very well). The YPI consists of 10 subscales (with five items each) designed in line with Cooke and Michie's (2001) three-dimensional conceptualization of the psychopathy construct, namely, the Grandiose-Manipulative dimension, the Callous-Unemotional dimension, and the Impulsive-Irresponsible dimension. More specifically, the Grandiose-Manipulative dimension consists of the Dishonest Charm, Grandiosity, Lying, and Manipulation subscales; the Callous-Unemotional dimension consists of the Callousness, Unemotionality, and Remorselessness subscales; and the ImpulsiveIrresponsible dimension consists of the Impulsivity, Thrill-Seeking, and Irresponsibility subscales. Higher scores reflect an increased presence of the characteristics associated, namely, psychopathic traits. The Portuguese version of the YPI was used (Pechorro, Andershed, Ray, Maroco, \& Gonçalves, 2015; Pechorro, Ribeiro da Silva, Andershed, Rijo, \& Gonçalves, 2016; Pechorro, Ribeiro da Silva, Rijo, Gonçalves, \& Andershed, 2017). The internal consistency for the current study, estimated by Cronbach's alpha, was .94.

The Inventory of Callous-Unemotional Traits (ICU; Essau et al., 2006; Kimonis et al., 2008)"is a 24-item self-report scale designed to assess CU traits in youth (see Roose et al., 2010) derived from the CU subscale of the Antisocial Process Screening Device (APSD; Frick \& Hare, 2001). Each item is scored on a 4-point ordinal scale (ranging from $0=$ not at all true to $3=$ definitely true). The ICU provides both a total score and three subscale scores, namely, Callousness, Uncaring, and Unemotional. Scores are calculated by reverse-scoring the positively worded items and then summing the items to obtain a total score. Higher scores indicate an increased presence of $\mathrm{CU}$ traits. The Portuguese validation of the ICU was used (Pechorro, Ray, Barroso, Maroco, \& Gonçalves, 2016; Pechorro, Hawes, Gonçalves, \& Ray, 2017). The internal consistency for the current study, estimated by Cronbach's alpha, was .86.

The Barratt Impulsiveness Scale version 11 (BIS-11; Patton et al., 1995; Stanford et al., 2009) is a 30-item self-report questionnaire designed to measure impulsiveness. Each item is scored on a 4-point ordinal scale (ranging from $1=$ rarely/never to $4=$ almost always/always). The BIS-11 contains six subscales that correspond to the six first-order factors: (a) Attention, (b) Cognitive Instability, (c) Motor, (d) Perseverance, (e) SelfControl, and (f) Cognitive Complexity. These six first-order factors converge into three second-order factors: (a) Attentional Impulsiveness (Attention and Cognitive Instability 
dimensions), (b) Motor Impulsiveness (Motor and Perseverance dimensions), and (c) Nonplanning Impulsiveness (Self-Control and Cognitive Complexity dimensions). The items are summed, and the higher the BIS-11 scores, the higher the impulsiveness level. A Portuguese version of the BIS-11, especially adapted for use with adolescents, was used (Pechorro, Ayala-Nunes, Nunes, Maia, \& Gonçalves, 2017; Pechorro, Ayala-Nunes, Ray, Nunes, \& Gonçalves, 2016; Pechorro, Marôco, Ray, \& Gonçalves, 2015). The internal consistency for the current study, estimated by Cronbach's alpha, was .85 .

The Reactive-Proactive Aggression Questionnaire (RPQ; Raine et al., 2006) is a self-report measure that distinguishes between reactive and proactive aggression. The RPQ consists of 23 items rated on a 3 -point ordinal scale $(0=$ never, $1=$ sometimes, 2 $=$ often). A total of 11 items assess reactive aggression (e.g., "Reacted angrily when provoked by others") and 12 items assess proactive aggression (e.g., "Hurt others to win a game"). Summed scores provide a measure of reactive or proactive aggression, as well as total aggression. Higher scores indicate higher levels of aggression. The RPQ is appropriate for use with youth in late adolescence and young adults. The Portuguese version of the RPQ was used (Pechorro, Kahn, Ray, Raine, \& Gonçalves, 2017; Pechorro, Ray, Raine, Maroco, \& Gonçalves, 2015). Internal consistency for the present study, estimated by Cronbach's alpha, was .90 .

The Social Anxiety Scale for Adolescents (SAS-A; La Greca \& Lopez, 1998) is an 18-item self-report scale designed to assess subjective experience of social anxiety in adolescents. Each item is rated on a 5-point ordinal scale (ranging from $0=$ not at all to 4 = all the time). Three distinct subscales have been identified: Fear of Negative Evaluation (FNE; eight items), Social Avoidance and Distress-New subscale (SADNew; six items), and Social Avoidance and Distress-General subscale (SAD-General; four items). The FNE subscale reflects fears, concerns, or worries regarding negative evaluations from peers, the SAD-New reflects social avoidance and distress with new social situations or unfamiliar peers, and the SAD-General reflects more generalized or pervasive social distress, discomfort, and inhibition. Scores are obtained by summing the ratings for the items comprising each subscale. The Portuguese validation of the SAS-A (Pechorro, Ayala-Nunes, Nunes, Maroco, \& Gonçalves, 2016) was used. Internal consistency for the present study, estimated by Cronbach's alpha, was .93.

The Sellin-Wolfgang Index of Crime Seriousness (ICS; Wolfgang et al., as cited in White et al., 1994) is a classification scheme for coding the seriousness of crimes based on official court reports. Level 0 consists of no delinquency. Level 1 consists of minor delinquency committed at home such as stealing minor amounts of money from mother's purse. Level 2 consists of minor delinquency outside the home including shoplifting something worth less than 5 euros, vandalism, and minor fraud (e.g., not paying bus fare). Level 3 consists of moderately serious delinquency such as any theft over 5 euros, gang fighting, carrying weapons, and joyriding. Level 4 consists of serious delinquency such as car theft and breaking and entering. Level 5 consists of having performed at least two of each of the behaviors in the previous level.

A CD scale was also created based on the 15 items used to assess CD (see, for example, Skilling, Quinsey, \& Craig, 2001). The 15 dichotomous items (coded $0=$ No; $1=$ Yes) were summated to obtain a total continuous score. Thus, higher scores 
indicate a higher number of positively endorsed indicators of $\mathrm{CD}$. Based on the Kuder-Richardson coefficient, the internal consistency of the CD scale was considered good (.89).

In addition, a questionnaire was constructed to describe the sociodemographic and criminal characteristics of the participants. This questionnaire included variables such as participants' age, ethnic group, geographic classification of residence (rural vs. urban), level of schooling completed, SES, parental marital status, previous use of physical violence (coded $0=$ No, $1=$ Yes), alcohol abuse, and drug use (these last two coded as 5-point ordinal scales from $0=$ almost never/never to $4=$ almost always/ always). SES was measured by considering both parental level of education and profession, appropriate to the Portuguese context. DSM-5's Conduct Disorder diagnosis (CD; APA, 2013) was assessed only regarding the forensic sample by the first and last authors of this article, using the official diagnostic criteria (i.e., the standard method described in the DSM-5). The prevalence of CD found in the current forensic sample was $85.4 \%$.

\section{Procedures}

Authorization to validate the NPI-13 in Portugal was obtained from the first author of the questionnaire (Gentile et al., 2013). Appropriate procedures (e.g., avoiding item bias or differential item functioning) were followed during the translation and retroversion (Hambleton, Merenda, \& Spielberger, 2005). The first and last authors of this article, who made sure that young people would be able to properly understand the meaning of the items, completed the initial translation from English into Portuguese. A native English speaker with considerable professional experience in translating psychology-related scientific texts then independently translated the questionnaire back into English. No significant differences were found between the back-translation and the original version, demonstrating that the translated items had the same or very similar meanings as the original English items.

The current sample was recruited from two difference sources. First, juvenile detention centers managed by the Portuguese Ministry of Justice that admit female detainees served as recruitment sites for the sample of detained female juveniles. The primary investigator obtained authorization to recruit detained youths from the General Directorate of Reintegration and Prison Services of the Portuguese Ministry of Justice. The participation rate was approximately $89 \%$. Motives for nonparticipation included refusal to participate $(6 \%)$, inability to participate due to not understanding the Portuguese language $(4 \%)$, and inability to participate due to security issues $(1 \%)$. Second, public schools of the Lisbon, Algarve, and Coimbra regions served as recruitment sites for the community sample. The primary investigator obtained authorization from the General Directorate of Education of the Portuguese Ministry of Education to conduct recruitment within schools. The participation rate for the community sample was approximately $84 \%$. Parental consent was obtained for all those agreeing to participate. The measures were administered by means of individual face-to-face interviews in an appropriate setting. Some of the information (e.g., sociodemographic 
variables) was obtained from self-reports, and institutional files were used to complement the information obtained (e.g., prior criminal activity and detentions).

The data were analyzed using SPSS Statistics v24 (IBM Corp., 2016) and EQS 6.3 (Bentler \& Wu, 2015). The factor structure was assessed with CFA performed in EQS 6.3, with robust maximum likelihood (ML) estimation (Byrne, 2006). Goodness-of-fit indices were calculated, including Satorra-Bentler chi-square/ degrees of freedom, comparative fit index (CFI), incremental fit index (IFI), root mean square error of approximation (RMSEA), and Akaike information criterion (AIC). A chi-square/degrees of freedom value $<5$ is considered acceptable, a value $\leq 2$ is considered good, and a value of 1 very good (Maroco, 2014; West, Taylor, \& $\mathrm{Wu}, 2012)$. A CFI $\geq .90$ and RMSEA $\leq .08$ indicate adequate fit, whereas a CFI $\geq .95$ and RMSEA $\leq .06$ indicate good model fit (Byrne, 2006). The IFI, also known as Bollen's IFI, is relatively insensitive to sample size; values that exceed .90 are regarded as acceptable (Maroco, 2014). Regarding the AIC, lower values indicate a better relative quality of the model as compared with alternative model's formulations (West et al., 2012). The CFA was performed on the original scale items, and items with standardized loadings above .30 were retained. Modification indices were considered to check whether any modifications would significantly improve the measurement model. Polychoric correlation matrixes with robust estimation methodologies were used to perform the CFAs on the ordinal items because they provide more accurate estimates (Byrne, 2006).

Kuder-Richardson coefficients (i.e., Cronbach's alpha for dichotomous items) and omega coefficients (considered satisfactory if above .70), mean interitem correlations (MIICs; considered good if within the .15-.50 range), and corrected item-total correlation ranges (CITCRs; considered adequate if above .20) were used to assess reliability (Clark \& Watson, 1995; Nunnally \& Bernstein, 1994). The omega coefficient was used in the present research because it is currently considered a better estimator of reliability than alpha (see Revelle \& Zinbarg, 2009). Pearson correlations were used to analyze associations between scale variables, Spearman correlations were used to analyze associations between ordinal variables and scale variables, and point-biserial correlations were used to analyze associations between nominal dichotomous variables and scale variables (Leech, Barrett, \& Morgan, 2015). Correlations were considered low if below .20, moderate if between .20 and .50, and high if above .50 .

\section{Results}

The first step in examining the psychometric properties of the Portuguese version of the NPI-13 was an attempt to replicate, by means of CFA using the ML robust method, the three-factor model proposed for this instrument (Gentile et al., 2013) among the forensic sample, school sample, and the total combined sample. The one-factor model was also analyzed. Shown in Table 1 are the goodness-of-fit indices we obtained regarding the one-factor, two-factor, and three-factor models. We were only able to find support for the three-factor model after removal of Item 9 (i.e., "I like to look at myself in the mirror") due to low item-loading across the three samples. This was somewhat 
Table I. Goodness-of-Fit Indices of the NPI-I 3 Among the Different Samples.

\begin{tabular}{|c|c|c|c|c|c|}
\hline NPI-I3 & $\mathrm{S}-\mathrm{B} \chi^{2} / \mathrm{df}$ & IFI & CFI & RMSEA & AIC \\
\hline \multicolumn{6}{|c|}{ Forensic $(n=103)$} \\
\hline One-factor ${ }^{\mathrm{a}}$ & $\mathrm{I} .77$ & .94 & .95 & $.09(.06-.11)$ & -14.25 \\
\hline Two-factor ${ }^{\mathrm{a}}$ & 1.69 & .95 & .95 & $.08(.05-.11)$ & -19.00 \\
\hline Three-factor ${ }^{a}$ & 1.62 & .97 & .97 & $.08(.05-.10)$ & -18.43 \\
\hline \multicolumn{6}{|l|}{ School $(n=274)$} \\
\hline One-factor ${ }^{b}$ & 3.83 & .88 & .88 & $.09(.10-.12)$ & 113.42 \\
\hline Two-factorb & 3.76 & .88 & .88 & $.09(.10-.11)$ & 107.39 \\
\hline Three-factorb & 2.75 & .94 & .94 & $.08(.06-.10)$ & 35.33 \\
\hline \multicolumn{6}{|l|}{ Total $(N=377)$} \\
\hline One-factor ${ }^{c}$ & 3.68 & .94 & .94 & .09 (.07-. 10$)$ & 104.16 \\
\hline Two-factorc & 3.50 & .95 & .95 & .08 (.07-.09) & 91.51 \\
\hline Three-factor ${ }^{c}$ & 2.53 & .97 & .97 & $.06(.05-.08)$ & 24.71 \\
\hline
\end{tabular}

Note. NPI- 3 = Narcissistic Personality Inventory short version; S-B $\chi^{2}=$ Satorra-Bentler chi-square; $d f=$ degrees of freedom; IFI = incremental fit index; CFI = comparative fit index; RMSEA $(90 \% \mathrm{Cl})$ $=$ root mean square error of approximation ( $90 \%$ confidence interval); $\mathrm{AIC}=\mathrm{Akaike}$ information criterion; $M L=$ maximum likelihood; Two-factor = combining LA and GE subscales; LA = Leadership/ Authority; GE = Grandiose Exhibitionism.

alncluded error covariance between Items I and 2, 5 and 7, 6 and 8.

blncluded error covariance between Items 5 and 7, I and 2, 6 and 8 .

clncluded error covariance between Items I and 2, 5 and 7, 6 and 8.

unexpected considering this item had a relatively high loading on Gentile et al.'s (2013) study, but it is important to mention that they used mixed-gender samples.

Table 2 displays the item loadings for the three-factor structure of the NPI-13 across the three samples. As seen in the table, all items loaded above .30 on the intended factor, with the exception of Item 9 of the GE. Thus, Item 9 was removed and is not included in the remaining statistical procedures.

Table 3 presents the correlations between the NPI-13 total and its dimensions across the three samples. As expected, the strength of these correlations was moderate to high positive correlations. In addition, the order of magnitude of the strength of these correlations was relatively consistent across the three samples, with the exception of Factor 2. Specifically, the correlations between the EE and LA were the strongest, whereas the correlations between the EE and GE are the weakest across all three samples.

Table 4 displays the Kuder-Richardson coefficients, the omega coefficients, the MIICs, and the CITCRs for the NPI-13 and its dimensions. It is important to note the low Kuder-Richardson coefficients found for the EE dimensions across all three samples.

The correlations with criterion variables and the NPI-13 across the different samples are presented in Table 5. The convergent validity of the NPI-13 total and its dimensions with the APSD-SR, the YPI, the ICU, the BIS-11, and the RPQ revealed mostly moderate and moderately high statistically significant positive correlations. 
Table 2. Item loadings and item prevalence for the confirmatory 3-factor structure of the $\mathrm{NPI}-\mathrm{I} 3$ among the different samples.

\begin{tabular}{|c|c|c|c|c|}
\hline Items & $\begin{array}{l}\% \text { Prev } \\
\text { Item T }\end{array}$ & $\begin{array}{c}\text { Factor I } \\
\text { F/S/T }\end{array}$ & $\begin{array}{c}\text { Factor } 2 \\
\text { F/S/T }\end{array}$ & $\begin{array}{c}\text { Factor } 3 \\
\text { F/S/T }\end{array}$ \\
\hline \multicolumn{5}{|l|}{ Leadership/Authority (LA) } \\
\hline $\begin{array}{l}\text { I. I like having authority over other } \\
\text { people. }\end{array}$ & $19.9 \%$ & $.75 / .66 / .69$ & - & - \\
\hline 2. I have a strong will to power. & $25.2 \%$ & $.63 / .55 / .59$ & - & - \\
\hline $\begin{array}{l}\text { 3. People always seem to recognize my } \\
{[\ldots]}\end{array}$ & $24.4 \%$ & $.46 / .59 / .55$ & - & - \\
\hline 4. I am a born leader. & $32.1 \%$ & $.60 / .57 / .60$ & - & - \\
\hline Factor Mean $(S D)$ Forensic sample $(n=103)$ & & $\mathrm{I} .47(\mathrm{I} .46)$ & & \\
\hline Factor Mean (SD) School sample $(n=274)$ & & $.85(1.21)$ & & \\
\hline Factor Mean (SD) Total sample $(N=377)$ & & $1.02(1.31)$ & & \\
\hline \multicolumn{5}{|l|}{ Grandiose Exhibitionism (GE) } \\
\hline 5. I know that I am a good person $[. .$.$] .$ & $25.2 \%$ & - & $.43 / .44 / .49$ & - \\
\hline 6. I like to show off my body. & $15.9 \%$ & - & $.73 / .36 / .58$ & - \\
\hline 7. I like to look at my body. & $31.3 \%$ & - & $.37 / .35 / .42$ & - \\
\hline $\begin{array}{l}\text { 8. I will usually show off if I get the } \\
\text { chance. }\end{array}$ & $18.3 \%$ & - & $.74 / .48 / .65$ & - \\
\hline 9. I like to look at myself in the mirror. & $63.1 \%$ & - & $-1-1-$ & - \\
\hline Factor Mean (SD) Forensic sample $(n=103)$ & & & $2.43(1.67)$ & \\
\hline Factor Mean (SD) School sample $(n=274)$ & & & $1.20(1.21)$ & \\
\hline Factor Mean (SD) Total sample $(N=377)$ & & & $1.54(1.45)$ & \\
\hline \multicolumn{5}{|l|}{ Entitlement/Exploitativeness (EE) } \\
\hline I0. I find it easy to manipulate people. & $25.7 \%$ & - & - & $.38 / .42 / .44$ \\
\hline $\begin{array}{l}\text { II. I insist upon getting the respect that } \\
{[\ldots] \text {. }}\end{array}$ & $51.9 \%$ & - & - & $.43 / .48 / .46$ \\
\hline 12. I expect a great deal from other people. & $33.4 \%$ & - & - & $.56 / .49 / .53$ \\
\hline I3. I will never be satisfied until I get [...]. & $29.4 \%$ & - & - & $.73 / .72 / .73$ \\
\hline Factor Mean (SD) Forensic sample $(n=103)$ & & & & $1.83(1.30)$ \\
\hline Factor Mean (SD) School sample $(n=274)$ & & & & $1.28(1.21)$ \\
\hline Factor Mean (SD) Total sample $(N=377)$ & & & & $1.44(1.26)$ \\
\hline
\end{tabular}

Note. NPI-I 3 = Narcissistic Personality Inventory short version; F/S/T samples = Forensic/School/Total samples; \% Prev item T = Percentage of prevalence of each item among the Total sample.

For the most part, the correlations among the subscales of the NPI and criterion measures were similar in direction and magnitude. It is somewhat surprising that the correlations between the LA dimension of the NPI-13 and all three measures of psychopathy exhibited the strongest correlations with all three measures of psychopathy across the different samples given that the EE and GE are more indicative of the maladaptive aspects of narcissism. The correlations with the SAS-A were in the expected negative direction. 
Table 3. Zero-Order Intercorrelations for the NPI-I 3 and the Lower-Order Dimensions Among the Different Samples.

\begin{tabular}{|c|c|c|c|c|}
\hline & NPI- I 3 total & LA & GE & $\mathrm{EE}$ \\
\hline \multicolumn{5}{|c|}{ Forensic $(n=103)$} \\
\hline NPI-I 3 total & 1 & & & \\
\hline NPI-I3 LA & $.88 * * *$ & I & & \\
\hline NPI-I3 GE & $.80 * * * *$ & $.55^{* * * *}$ & 1 & \\
\hline NPI-I 3 EE & $.76 * * * *$ & $.57 * * *$ & $.34 * * * *$ & I \\
\hline \multicolumn{5}{|l|}{ School $(n=274)$} \\
\hline NPI-I 3 total & 1 & & & \\
\hline NPI-I3 LA & $.82^{* * *}$ & 1 & & \\
\hline NPI-I3 GE & $.73^{* * * *}$ & $.49 * * *$ & I & \\
\hline NPI-I 3 EE & $.80 * * *$ & $.56 * * *$ & $.32 * * *$ & I \\
\hline \multicolumn{5}{|l|}{ Total $(N=377)$} \\
\hline NPI-I 3 total & 1 & & & \\
\hline NPI-I3 LA & $.87^{* * *}$ & 1 & & \\
\hline NPI-I3 GE & $.78 * * * *$ & $.55^{* * * *}$ & 1 & \\
\hline NPI-I3 EE & $.79 * * *$ & $.58 * * *$ & $.37 * * *$ & I \\
\hline
\end{tabular}

Note. NPI-I 3 = Narcissistic Personality Inventory short version; LA = Leadership/Authority dimension; $\mathrm{GE}=$ Grandiose Exhibitionism dimension; $\mathrm{EE}=$ Entitlement/Exploitativeness dimension.

$* * *$ Significant at the .001 level.

Correlations with other variables were also analyzed. Statistically significant correlations were found between the NPI-13 total and its subscales with age of crime onset, age of first problem with the law, CD symptoms (scored as a scale), crime seriousness, previous violent crimes, alcohol abuse, and cannabis use. Among the total sample, only the correlation between age of first problem with the law and the GE dimension was not significant. However, among the school sample, several variables did not reach statistical significance, namely, age of crime onset, crime seriousness, previous violent crimes, and cannabis use.

\section{Discussion}

The present study examined the psychometric properties of the NPI-13 among a female forensic sample and community adolescents. CFA suggested that the threefactor first-order intercorrelated model was the best fitting model, despite the fact one item (i.e., "I like to look at myself in the mirror") had to be excluded due to low factor loading. Perhaps this was because "looking in the mirror" is a very common behavior among most young females and, therefore, does not discriminate across dimensions of narcissism in the current sample. Nonetheless, the results confirm the multidimensional conceptualization of narcissism among Portuguese females and replicates previous work in samples of adults (e.g., Gentile et al., 2013). 
Table 4. Kuder-Richardson Coefficients, Omega Coefficients, MIICs, and CITCRs for the $\mathrm{NPI}$ - 3 Among the Different Samples.

\begin{tabular}{|c|c|c|c|c|}
\hline & K-R coefficient & Omega coefficient & MIIC & CITCR \\
\hline \multicolumn{5}{|l|}{ Forensic sample $(n=103)$} \\
\hline NPI-I 3 total & .84 & .88 & .30 & $.28-.71$ \\
\hline NPI-I 3 Leadership/Authority & .76 & .85 & .44 & $.35-.69$ \\
\hline $\begin{array}{l}\text { NPI-I3 Grandiose } \\
\text { Exhibitionism }\end{array}$ & .78 & .83 & .47 & $.54-.65$ \\
\hline $\begin{array}{l}\text { NPI-I } 3 \text { Entitlement/ } \\
\text { Exploitativeness }\end{array}$ & .56 & .75 & .24 & $.21-.53$ \\
\hline \multicolumn{5}{|l|}{ School sample $(n=274)$} \\
\hline NPI-I 3 total & .81 & .88 & .27 & $.35-.61$ \\
\hline NPI-I 3 Leadership/Authority & .74 & .85 & .41 & $.37-.67$ \\
\hline $\begin{array}{l}\text { NPI- I } 3 \text { Grandiose } \\
\text { Exhibitionism }\end{array}$ & .67 & .78 & .33 & $.30-.63$ \\
\hline $\begin{array}{l}\text { NPI- I } 3 \text { Entitlement/ } \\
\text { Exploitativeness }\end{array}$ & .60 & .76 & .27 & $.21-.48$ \\
\hline \multicolumn{5}{|l|}{ Total sample $(N=377)$} \\
\hline NPI-I 3 total & .84 & .90 & .30 & $.35-.66$ \\
\hline NPI-I 3 Leadership/Authority & .76 & .86 & .44 & $.46-.69$ \\
\hline $\begin{array}{l}\text { NPI-I3 Grandiose } \\
\text { Exhibitionism }\end{array}$ & .76 & .84 & .44 & $.48-.67$ \\
\hline $\begin{array}{l}\text { NPI- I } 3 \text { Entitlement/ } \\
\text { Exploitativeness }\end{array}$ & .60 & .76 & .26 & $.23-.51$ \\
\hline
\end{tabular}

Note. K-R coefficient $=$ Kuder-Richardson coefficient; MIIC = mean interitem correlation; CITCR = corrected item-total correlation range; NPI- I3 = Narcissistic Personality Inventory short version.

Within both samples of forensic and community adolescents, internal consistency measured by the Kuder-Richardson coefficient was good for the total NPI-13 score and two of the associated subscales. The exception was the EE subscale with values systematically below the recommended cutoff (i.e., .70; Kaplan \& Saccuzzo, 2013). This was somewhat expected given that previous studies (e.g., Gentile et al., 2013) also found these kinds of low values regarding the EE subscale. In terms of the Omega coefficient, the values were good for the total NPI-13 and all subscales. Adequate homogeneity was present between the items with MIICs falling within the recommended value range (i.e., .15-.50; Clark, \& Watson, 1995) and correct itemtotal correlation ranges above the recommended value (i.e., .20; Nunnally \& Bernstein, 1994).

Evidence of adequate convergent and discriminant validity (American Educational Research Association, American Psychological Association, \& National Council for Measurement in Education, 2014) was present with the NPI-13 demonstrating the expected associations with external correlates. Specifically, the NPI-13 and its subscales were significantly and positively associated with self-reported measures of psychopathy, 
Table 5. Correlations of the NPI-I 3 With Other Measures and Variables Among the Different Samples.

\begin{tabular}{|c|c|c|c|c|}
\hline & NPI- I 3 total & $\begin{array}{l}\text { Leadership/ } \\
\text { Authority }\end{array}$ & $\begin{array}{l}\text { Grandiose/ } \\
\text { Exhibitionism }\end{array}$ & $\begin{array}{c}\text { Entitlement/ } \\
\text { Exploitativeness }\end{array}$ \\
\hline \multicolumn{5}{|c|}{ Forensic/school $(n=103 / n=274)$} \\
\hline APSD-SR & $.38^{* * *} / .33^{* * *}$ & $.4 \mid * * * 1.29 * * *$ & $.25 * * * 1.23 * * *$ & $.25 * / .27 * * *$ \\
\hline YPI & $.57 * * * / .54 * * *$ & $.52 * * * / .51 * * *$ & $.45^{* * *} / .37 * * *$ & $.4 I^{* * *} / .4 I^{* * *}$ \\
\hline ICU & $.14^{n s} /\left..1\right|^{n s}$ & $.21 * 1.17 * *$ & $.05^{n s} /-.04^{n s}$ & $\left..1\right|^{n s} / .14^{*}$ \\
\hline BIS-II & $.44 * * * / .20 * *$ & $.40 * * * 1.19 * *$ & $.28 * * / .14 *$ & $.41 * * * / .13 *$ \\
\hline $\mathrm{RPQ}$ & $.54 * * * / .38 * * *$ & $.46 * * * / .35 * * *$ & $.27 * * / .21 * * *$ & $.62^{* * *} / .33^{* * *}$ \\
\hline SAS-A & $.09^{n s} /-.16^{*}$ & $.13^{n s} /-.14^{*}$ & $.08^{n s} /-.17^{* *}$ & $-.02^{n s} /-.07^{n s}$ \\
\hline $\mathrm{ACO}$ & $-.38^{* * *} /-.29^{n s}$ & $-.40^{* * * *} /-.36^{n s}$ & $-.15^{n s} /-.35^{n s}$ & $-.4 I^{* * *} /-.05^{\text {ns }}$ \\
\hline AFPL & $-.22 * /-.83 *$ & $-.32 * * /-.95^{* * *}$ & $.08^{\text {ns }} /-.95^{* * * *}$ & $-.36 * * * / .28^{n s}$ \\
\hline ICS & $.27^{* *} / .06^{n s}$ & $.27^{* *} / .04^{\text {ns }}$ & $.1 \mathrm{I}^{\mathrm{ns}} / .02^{\mathrm{ns}}$ & $.29 * * 1.07^{\text {ns }}$ \\
\hline PVC & $.25 * / .00^{n s}$ & $.30 * * / .04^{n s}$ & $.07^{n s} / .0 I^{n s}$ & $.24 * /-.05^{n s}$ \\
\hline CD symptoms & $.38 * * * / .19 * *$ & $.43^{* * *} / .22 * *$ & $.14^{n s} / .12^{*}$ & $.38 * * * /\left..1\right|^{n s}$ \\
\hline Alcohol & $.08^{n s} / .21^{* * *}$ & $.1 I^{n s} / .16^{* *}$ & $-\left..1\right|^{n s} / .17^{* *}$ & $.28 * * 1.22 * * *$ \\
\hline Cannabis & $.15^{n s} / .10^{n s}$ & $.25 * / .04^{n s}$ & $.0 \mathrm{I}^{\mathrm{ns}} / .02^{\mathrm{ns}}$ & $.13^{n s} / .17^{* *}$ \\
\hline \multicolumn{5}{|l|}{ Total $(N=377)$} \\
\hline APSD-SR & $.44 * * *$ & $.38 * * *$ & $.37 * * *$ & $.32 * * * *$ \\
\hline YPI & $.61^{* * *}$ & $.54 * * *$ & $.50 * * *$ & $.44 * * *$ \\
\hline ICU & $.21 * * *$ & $.23 * * *$ & $.11^{*}$ & $.19 * * *$ \\
\hline BIS-II & $.36 * * *$ & $.31 * * *$ & $.29 * * *$ & $.26 * * *$ \\
\hline RPQ & $.53^{* * *}$ & $.43^{* * *}$ & $.4 I^{* * *}$ & $.45^{* * *}$ \\
\hline SAS-A & $-.12^{*}$ & $-.08^{n s}$ & $-.12 *$ & $-.07^{n s}$ \\
\hline $\mathrm{ACO}$ & $-.42 * * *$ & $-.43 * * *$ & $-.27^{* * *}$ & $-.35 * * *$ \\
\hline AFPL & $-.28 * * *$ & $-.36 * * *$ & $-.0 I^{n s}$ & $-.36 * * *$ \\
\hline ICS & $.35 * * *$ & $.24 * * *$ & $.36 * * *$ & $.24 * * *$ \\
\hline PVC & $.34 * * *$ & $.27 * * *$ & $.35 * * *$ & $.22 * * *$ \\
\hline CD symptoms & $.42 * * *$ & $.34 * * *$ & $.38 * * *$ & $.28 * * *$ \\
\hline Alcohol & $.27 * * *$ & $.20 * * *$ & $.22^{* * *}$ & $.29 * * *$ \\
\hline Cannabis & $.29 * * *$ & $.22 * * *$ & $.25^{* * *}$ & $.25 * * *$ \\
\hline
\end{tabular}

Note. NPI- 3 = Narcissistic Personality Inventory short version; APSD-SR = Antisocial Process Screening Device-Self-Report; YPI = Youth Psychopathic Traits Inventory; ICU = Inventory of CallousUnemotional Traits; BIS-II = Barratt Impulsiveness Scale-I I; RPQ = Reactive-Proactive Aggression Questionnaire; SAS-A = Social Anxiety Scale for Adolescents; $A C O=$ age of crime onset; $A F P L=$ age of first problem with the law; ICS = Index of Crime Seriousness; $P V C=$ previous violent crimes; $C D$ symptoms $=$ DSM- 5 Conduct Disorder symptoms scored as a scale.

*Significant at the .05 level. **Significant at the $.0 \mathrm{I}$ level. ${ }^{* * *}$ Significant at the $.00 \mathrm{I}$ level. $n s=$ nonsignificant.

CU traits, impulsivity, and aggression. In general, the different correlations of NPI-13 subscales with external criteria corroborate their discriminant validity (e.g., with SASA). The other correlations are somewhat similar across the different subscales, more or less corroborating the presence of the same latent construct. 
The criterion-related validity of the NPI-13 and its subscales with the age of crime onset and age of first problem with the law revealed mostly negative moderate statistically significant associations. These correlations are consistent with previous research (e.g., Forth, Kosson, \& Hare, 2003) showing negative associations between dimensions of psychopathy-related traits, such as narcissism, and the age of crime onset variable. Positive moderate statistically significant correlations emerged between the NPI-13 and measures of criminal behavior such as crime seriousness and previous violent crime. Because narcissism is considered a facet of the psychopathy construct (Feilhauer \& Cima, 2013), we expected to find these positive associations with measures of externalizing behavior, similar to those identified in prior studies (e.g., Dolan \& Rennie, 2006; Poythress, Dembo, Wareham, \& Greenbaum, 2006).

The correlations with DSM-5's (APA, 2013) Conduct Disorder symptoms revealed moderate associations. The high prevalence of $\mathrm{CD}$ found in the current female forensic sample $(85.4 \%)$ was somewhat higher than those typically found among forensic samples (see Sevecke \& Kosson, 2010).

The correlations of the NPI-13 and its subscales with alcohol abuse and cannabis use revealed mostly positive moderate low statistically significant correlations. The EE dimension manifested the highest correlation with alcohol and cannabis use. These results are consistent with previous research showing that narcissism is closely associated with maladaptive variables and outcomes (e.g., Ackerman et al., 2011; Gentile et al., 2013).

The results should be considered within the context of some limitations. First, the current study relied almost entirely on self-reports, which may have increased the possibility of shared method variance inflating associations between study variables. However, most findings from the current study are relatively consistent with theoretical considerations and past empirical work on the NPI-13. Second, the cross-sectional design and analyses in the current study do not allow us to infer causality in terms of the associations between narcissism and other constructs measured. In addition, the cross-sectional nature of the current study does not allow for the examination of temporal stability, analysis of test-retest, or associated outcomes for the NPI-13. While Gentile et al. (2013) also argued for the need of investigating test-retest reliability, this study had only a small forensic sample of females, and thus, future research is required to fill this research gap. Despite these limitations, the NPI-13 appears to be a promising brief measure of narcissism. We hope that our study may promote future research on the narcissism construct among youths and contributes to a more generalized use of brief measures of narcissism.

\section{Acknowledgment}

The authors thank the following Portuguese juvenile detention centers: Bela Vista, Navarro de Paiva, and Santa Clara.

\section{Declaration of Conflicting Interests}

The author(s) declared no potential conflicts of interest with respect to the research, authorship, and/or publication of this article. 


\section{Funding}

The author(s) disclosed receipt of the following financial support for the research, authorship, and/or publication of this article: This study was supported by the Portuguese Foundation for Science and Technology (FCT; Grant SFRH/BPD/86666/2012) with cofinancing of the European Social Fund (POPH/FSE), the Portuguese Ministry of Education and Science (MEC), and FEDER (PT2020 Partnership Agreement; UID/PSI/01662/2013). This study was also partially supported through project UID/SOC/04020/2013

\section{References}

Ackerman, R., Witt, E., Donnellan, M., Trzesniewski, K., Robins, R., \& Kashy, D. (2011). What does the Narcissistic Personality Inventory really measure? Assessment, 18, 67-87. doi: $10.1177 / 1073191110382845$

American Educational Research Association, American Psychological Association, \& National Council for Measurement in Education. (2014). Standards for educational and psychological testing. Washington, DC: American Educational Research Association.

American Psychiatric Association. (1980). Diagnostic and statistical manual of mental disorders (3rd ed.). Washington, DC: Author.

American Psychiatric Association. (2013). Diagnostic and statistical manual of mental disorders (5th ed.). Arlington, VA: American Psychiatric Publishing.

Ames, D., Rose, P., \& Anderson, P. (2006). The NPI-16 as a short measure of narcissism. Journal of Research in Personality, 40, 440-450. doi:10.1016/j.jrp.2005.03.002

Andershed, H., Gustafson, S. B., Kerr, M., \& Stattin, H. (2002). The usefulness of self-reported psychopathy-like traits in the study of antisocial behaviour among non-referred adolescents. European Journal of Personality, 16, 383-402. doi:10.1002/per.455

Barry, C. T., Frick, P. J., \& Killian, A. L. (2003). The relation of narcissism and self-esteem to conduct problems in children: A preliminary investigation. Journal of Clinical Child \& Adolescent Psychology, 32, 139-152. doi:10.1207/S15374424JCCP3201_13

Barry, C. T., Grafeman, S. J., Adler, K. K., \& Pickard, J. D. (2007). The relations among narcissism, self-esteem, and delinquency in a sample of at-risk adolescents. Journal of Adolescence, 30, 933-942. doi:10.1016/j.adolescence.2006.12.003

Bentler, P., \& Wu, E. (2015). Supplement to EQS 6.3 for Windows user's guide. Temple City, CA: Multivariate Software.

Bodlund, O., Ekselius, L., \& Lindström, E. (1993). Personality traits and disorders among psychiatric outpatients and normal subjects on the basis of SCID screen questionnaire. Nordic Journal of Psychiatry, 47, 425-433. doi:10.3109/08039489309104111

Brown, A., \& Maydeu-Olivares, A. (2011). Item response modeling of forced-choice questionnaires. Educational and Psychological Measurement, 71, 460-502. doi:10.1177/0013164410375112

Brown, A., \& Maydeu-Olivares, A. (2013). How IRT can solve problems of ipsative data in forced-choice questionnaires. Psychological Methods, 18, 36-52. doi:10.1037/a0030641

Brown, R. P., Budzek, K., \& Tamborski, M. (2009). On the meaning and measure of narcissism. Personality and Social Psychology Bulletin, 35, 951-964. doi:10.1177/0146167209335461

Bushman, B. J., \& Baumeister, R. F. (1998). Threatened egotism, narcissism, self-esteem, and direct and displaced aggression: Does self-love or self-hate lead to violence? Journal of Personality and Social Psychology, 75, 219-229. doi:10.1037/0022-3514.75.1.219

Byrne, B. (2006). Structural equation modeling with EQS: Basic concepts, applications, and programming. Mahwah, NJ: Lawrence Erlbaum. 
Calhoun, G., Glaser, B., Stefurak, T., \& Bradshaw, C. (2000). Preliminary validation of the Narcissistic Personality Inventory-Juvenile Offender. International Journal of Offender Therapy and Comparative Criminology, 44, 564-580. doi:10.1177/0306624X00445004

Caputo, A., Frick, P., \& Brodsky, S. (1999). Family violence and juvenile sex offending. Criminal Justice and Behavior, 26, 338-356. doi:10.1177/0093854899026003004

Carroll, L. (1987). A study of narcissism, affiliation, intimacy, and power motives among students in business administration. Psychological Reports, 61, 355-358. doi:10.2466/ pr0.1987.61.2.355

Cauffman, E. (2008). Understanding the female offender. The Future of Children, 18, 119-142. doi: $10.1353 /$ foc. 0.0015

Chabrol, H., Van Leeuwen, N., Rodgers, R., \& Séjourné, N. (2009). Contributions of psychopathic, narcissistic, Machiavellian, and sadistic personality traits to juvenile delinquency. Personality and Individual Differences, 47, 734-739. doi:10.1016/j.paid.2009.06.020

Chesney-Lind, M., \& Shelden, R. G. (2014). Girls, delinquency, and juvenile justice (4th ed.). Chichester, UK: Wiley-Blackwell.

Clark, L., \& Watson, D. (1995). Constructing validity: Basic issues in objective scale development. Psychological Assessment, 7, 309-319. doi:10.1037/1040-3590.7.3.309

Cooke, D., \& Michie, C. (2001). Refining the construct of psychopathy: Towards a hierarchical model. Psychological Assessment, 13, 171-188. doi:10.1037/1040-3590.13.2.171

Cross, C. P., Copping, L. T., \& Campbell, A. (2011). Sex differences in impulsivity: A metaanalysis. Psychological Bulletin, 137, 97-130. doi:10.1037/a0021591

Dolan, M., \& Rennie, C. (2006). Psychopathy checklist: Youth Version and Youth Psychopathic Traits Inventory: A comparison study. Personality and Individual Differences, 41, 779-789. doi:10.1016/j.paid.2006.03.021

Domino, G., \& Domino, M. (2006). Psychological testing: An introduction (2nd ed.). New York, NY: Cambridge University Press.

Emmons, R. A. (1984). Factor analysis and construct validity of the Narcissistic Personality Inventory.JournalofPersonality Assessment, 48,291-300.doi:10.1207/s15327752jpa4803_11

Emmons, R. A. (1987). Narcissism: Theory and measurement. Journal of Personality and Social Psychology, 52, 11-17. doi:10.1037/0022-3514.52.1.11

Essau, C., Sasagawa, S., \& Frick, P. (2006). Callous-unemotional traits in community sample of adolescents. Assessment, 13, 454-469. doi:10.1177/1073191106287354

Feilhauer, J., \& Cima, M. (2013). Youth psychopathy: Differential correlates of callousunemotional traits, narcissism, and impulsivity. Forensic Science International, 224, 1-7. doi:10.1016/j.forsciint.2012.10.016

Feilhauer, J., Cima, M., \& Arntz, A. (2012). Assessing callous-unemotional traits across different groups of youths: Further cross-cultural validation of the Inventory of CallousUnemotional Traits. International Journal of Law and Psychiatry, 35, 251-262. doi:10.1016/j.ijlp.2012.04.002

Forth, A., Kosson, D., \& Hare, R. (2003). Hare Psychopathy Checklist: Youth Version (PCL:YV): Technical manual. Toronto, Ontario, Canada: Multi-Health Systems.

Foster, J. D., \& Campbell, W. K. (2007). Are there such things as "narcissists" in social psychology? A taxometric analysis of the Narcissistic Personality Inventory. Personality and Individual Differences, 43, 1321-1332. doi:10.1016/j.paid.2007.04.003

Foster, J. D., Campbell, W. K., \& Twenge, J. M. (2003). Individual differences in narcissism: Inflated self-views across the lifespan and around the world. Journal of Research in Personality, 37, 469-486. doi:10.1016/S0092-6566(03)00026-6 
Frick, P., \& Hare, R. (2001). The Antisocial Process Screening Device (APSD): Technical manual. Toronto, ON: Multi-Health Systems.

Gentile, B., Miller, J., Hoffman, B., Reidy, D., Zeichner, A., \& Campbell, W. (2013). A test of two brief measures of grandiose narcissism: The Narcissistic Personality Inventory-13 and the Narcissistic Personality Inventory-16. Psychological Assessment, 25, 1120-1136. doi:10.1037/a0033192

Grijalva, E., Newman, D. A., Tay, L., Donnellan, M. B., Harms, P. D., Robins, R. W., \& Yan, T. (2015). Gender differences in narcissism: A meta-analytic review. Psychological Bulletin, 141, 261-310. doi:10.1037/a0038231

Hambleton, R., Merenda, P., \& Spielberger, C. (2005). Adapting educational and psychological tests for cross-cultural assessment. Mahwah, NJ: Lawrence Erlbaum.

Hare, R. (2003). Hare Psychopathy Checklist-Revised: Technical manual (2nd ed.). Toronto, Canada: Multi-Health Systems.

IBM Corp. (2016). IBM SPSS Statistics (Version 24). Chicago, IL: SPSS Inc.

Kaplan, R., \& Saccuzzo, D. (2013). Psychological testing: Principles, applications, and issues (8th ed.). Belmont, CA: Wadsworth Cengage Learning.

Kimonis, E. R., Frick, P. J., Skeem, J. L., Marsee, M. A., Cruise, K., Munoz, L. C., . . Morris, A. S. (2008). Assessing callous-unemotional traits in adolescent offenders: Validation of the Inventory of Callous-Unemotional Traits. International Journal of Law and Psychiatry, 31, 241-252. doi:10.1016/j.ijlp.2008.04.002

Klein, D. N., Riso, L. P., Donaldson, S. K., Schwartz, J. E., Anderson, R. L., Ouimette, P. C., . . . Aronson, T. A. (1995). Family study of early-onset dysthymia: Mood and personality disorders in relatives of outpatients with dysthymia and episodic major depression and normal controls. Archives of General Psychiatry, 52, 487-496. doi:10.1001/archpsyc. 1995.03950180073010

La Greca, A., \& Lopez, N. (1998). Social anxiety among adolescents: Linkages with peer relations and friendships. Journal of Abnormal Child Psychology, 26, 83-94. doi:10.1023/A:1022684520514

Lau, K. S., \& Marsee, M. A. (2013). Exploring narcissism, psychopathy, and Machiavellianism in youth: Examination of associations with antisocial behavior and aggression. Journal of Child and Family Studies, 22, 355-367. doi:10.1007/s10826-012-9586-0

Leech, N., Barrett, K., \& Morgan, G. (2015). SPSS for intermediate statistics: Use and interpretation (5th ed.). New York, NY: Routledge.

Lynam, D. R. (2011). Psychopathy and narcissism. In W. K. Campbell \& J. D. Miller (Eds.), The handbook of narcissism and narcissistic personality disorder: Theoretical approaches, empirical findings, and treatments (pp. 272-282). Hoboken, NJ: John Wiley.

Maffei, C., Fossati, A., Lingiardi, V., Madeddu, F., Borellini, C., \& Petrachi, M. (1995). Personality maladjustment, defenses, and psychopathological symptoms in nonclinical subjects. Journal of Personality Disorders, 9, 330-345. doi:10.1521/pedi.1995.9.4.330

Maroco, J. (2014). Análise de Equações Estruturais: Fundamentos teóricos, software \& aplicações [Structural equations analysis: Theoretical foundations, software and applications]. Pero Pinheiro, Portugal: ReportNumber.

Muñoz, L. C., Kimonis, E. R., Frick, P. J., \& Aucoin, K. J. (2013). Emotional reactivity and the association between psychopathy-linked narcissism and aggression in detained adolescent boys. Development and Psychopathology, 25, 473-485. doi:10.1017/S0954579412001186

Nunnally, J., \& Bernstein, I. (1994). Psychometric theory (3rd ed.). New York, NY: McGrawHill. 
Patton, J., Stanford, M., \& Barratt, E. (1995). Factor structure of the Barratt Impulsiveness Scale. Journal of Clinical Psychology, 51, 768-774. doi:10.1002/1097-4679.

Pechorro, P., Andershed, H., Ray, J., Maroco, J., \& Gonçalves, R. (2015). Validation of the Youth Psychopathic Traits Inventory and Youth Psychopathic Traits Inventory-Short among incarcerated juvenile delinquents. Journal of Psychopathology and Behavioral Assessment, 37, 576-586. doi:10.1007/s10862-015-9490-1

Pechorro, P., Ayala-Nunes, L., Nunes, C., Maia, A., \& Gonçalves, R. (2017). The Barratt Impulsiveness Scale-11 among a Portuguese sample of female juvenile delinquents and community youths. International Journal of Forensic Mental Health, 16, 46-57. doi:10.1080/ 14999013.2016.1235627

Pechorro, P., Ayala-Nunes, L., Nunes, C., Maroco, J., \& Gonçalves, R. (2016). The Social Anxiety Scale for Adolescents: Measurement invariance and psychometric properties among a school sample of Portuguese youths. Child Psychiatry \& Human Development, 47, 975-984. doi:10.1007/s10578-016-0627-6

Pechorro, P., Ayala-Nunes, L., Ray, J., Nunes, C., \& Gonçalves, R. (2016). Psychometric properties of the Portuguese version of the Barratt Impulsiveness Scale-11 among a school sample of male and female adolescents. Journal of Child and Family Studies, 25, 27532764. doi:10.1007/s10826-016-0453-2

Pechorro, P., Gentile, B., Ray, J. V., Nunes, C., \& Gonçalves, R. (2016). Adaptation of the Narcissistic Personality Inventory among a Portuguese sample of incarcerated juvenile offenders. Psychology, Crime \& Law, 22, 495-511. doi:10.1080/1068316X.2016.1168421

Pechorro, P., Hawes, S., Gonçalves, R., \& Ray, J. (2017). Psychometric properties of the Inventory of Callous-Unemotional Traits short version (ICU-12) among detained female juvenile offenders and community youths. Psychology, Crime \& Law, 23, 221-239. doi:10. 1080/1068316X.2016.1239724

Pechorro, P., Hidalgo, V., Nunes, C., \& Jiménez, L. (2016). Confirmatory factor analysis of the Antisocial Process Screening Device: Self-Report among incarcerated male juvenile offenders. International Journal of Offender Therapy and Comparative Criminology, 60, 1856-1872. doi:10.1177/0306624X15588903

Pechorro, P., Kahn, R., Ray, J., Raine, A., \& Gonçalves, R. A. (2017). Psychometric properties of the Reactive-Proactive Aggression Questionnaire among detained female juvenile delinquents and community youths. Criminal Justice and Behavior. Advance online publication. doi:10.1177/0093854816686395

Pechorro, P., Maroco, J., Poiares, C., \& Vieira, R. (2013). Validation of the Portuguese version of the Antisocial Process Screening Device Self-Report with a focus on delinquent behavior and behavior problems. International Journal of Offender Therapy and Comparative Criminology, 57, 112-126. doi:10.1177/0306624X11427174

Pechorro, P., Marôco, J., Ray, J., \& Gonçalves, R. (2015). Psychometric properties of the Barratt Impulsiveness Scale version 11 among a Portuguese sample of incarcerated juvenile offenders. Psychology, Crime \& Law, 21, 854-870. doi:10.1080/1068316X.2015.1054386

Pechorro, P., Ray, J., Barroso, R., Maroco, J., \& Gonçalves, R. (2016). Validation of the Inventory of Callous-Unemotional Traits among a Portuguese sample of detained juvenile offenders. International Journal of Offender Therapy and Comparative Criminology, 60, 349-365. doi:10.1177/0306624X14551256

Pechorro, P., Ray, J., Raine, A., Maroco, J., \& Gonçalves, R. (2015). The Reactive-Proactive Aggression Questionnaire: Validation among a Portuguese sample of incarcerated juvenile delinquents. Journal of Interpersonal Violence, Advance online publication. doi: $10.1177 / 0886260515590784$ 
Pechorro, P., Ribeiro da Silva, D., Andershed, H., Rijo, D., \& Gonçalves, R. A. (2016). The Youth Psychopathic Traits Inventory: Measurement invariance and psychometric properties among Portuguese youths. International Journal of Environmental Research and Public Health, 13, 852. doi:10.3390/ijerph13090852

Pechorro, P., Ribeiro da Silva, D., Rijo, D., Gonçalves, R. A., \& Andershed, H. (2017). Psychometric properties and measurement invariance of the Youth Psychopathic Traits Inventory-Short among Portuguese youths. Journal of Psychopathology and Behavioral Assessment. Advance online publication. doi:10.1007/s10862-017-9597-7

Poythress, N., Dembo, R., Wareham, J., \& Greenbaum, P. (2006). Construct validity of the Youth Psychopathic features Inventory (YPI) and the Antisocial Process Screening Device (APSD) with justice-involved adolescents. Criminal Justice and Behavior, 33, 26-55. doi: $10.1177 / 0093854805282518$

Raine, A., Dodge, K., Loeber, R., Gatzke-Kopp, L., Lynam, D., Reynolds, C., . . Liu, J. (2006). The Reactive-Proactive Aggression Questionnaire: Differential correlates of reactive and proactive aggression in adolescent boys. Aggressive Behavior, 32, 159-171. doi:10.1002/ab.20115

Raskin, R. N., \& Hall, C. S. (1979). A Narcissistic Personality Inventory. Psychological Reports, 45, 590. doi:10.2466/pr0.1979.45.2.590

Raskin, R., \& Terry, H. (1988). A principal-components analysis of the Narcissistic Personality Inventory and further evidence of its construct validity. Journal of Personality and Social Psychology, 54, 890-902. doi:10.1037/0022-3514.54.5.890

Raskin, R., \& Shaw, R. (1988). Narcissism and the use of personal pronouns. Journal of Personality, 56, 393-404. doi:10.1111/j.1467-6494.1988.tb00892.x

Revelle, W., \& Zinbarg, R. (2009). Coefficients alpha, beta, omega, and the GLB: Comments on Sijtsma. Psychometrika, 74, 145-154. doi:10.1007/s11336-008-9102-z

Rhodewalt, F., \& Morf, C. C. (1995). Self and interpersonal correlates of the Narcissistic Personality Inventory: A review and new findings. Journal of Research in Personality, 29, 1-23. doi:10.1006/jrpe.1995.1001

Rhodewalt, F., \& Morf, C. C. (1998). On self-aggrandizement and anger: Temporal analysis of narcissism and affective reactions to success and failure. Journal of Personality and Social Psychology, 74, 672-685. doi:10.1037/0022-3514.74.3.672

Robins, R. W., \& Trzesniewski, K. H. (2005). Self-esteem development across the lifespan. Current Directions in Psychological Science, 14, 158-162. doi:10.1111/j.09637214.2005.00353.x

Roose, A., Bijttebier, P., Decoene, S., Claes, L., \& Frick, P. (2010). Assessing the affective features of psychopathy in adolescence: A further validation of the Inventory of Callous and Unemotional Traits. Assessment, 17, 44-57. doi:10.1177/1073191109344153

Samuels, J., Eaton, W. W., Bienvenu, O. J., Brown, C. H., Costa, P. T., \& Nestadt, G. (2002). Prevalence and correlates of personality disorders in a community sample. British Journal of Psychiatry, 180, 536-542. doi:10.1192/bjp.180.6.536

Sevecke, K., \& Kosson, D. (2010). Relationships of child and adolescent psychopathy to other forms of psychopathology. In R. Salekin \& D. Lynam (Eds.), Handbook of child and adolescent psychopathy (pp. 284-314). New York, NY: Guilford Press.

Shedler, J., \& Westen, D. (2007). The Shedler-Westen Assessment Procedure (SWAP): Making personality diagnosis clinically meaningful. Journal of Personality Assessment, 89, 41-55. doi:10.1080/00223890701357092

Skilling, T., Quinsey, V., \& Craig, W. (2001). Evidence of a taxon underlying serious antisocial behavior in boys. Criminal Justice and Behavior, 28, 450-470. doi:10.1177/ 009385480102800404 
Stanford, M., Mathias, C., Dougherty, D., Lake, S., Anderson, N., \& Patton, J. (2009). Fifty years of the Barratt Impulsiveness Scale: An update and review. Personality and Individual Differences, 47, 385-395. doi:10.1016/j.paid.2009.04.008

Stinson, F. F., Dawson, D. A., Goldstein, R. B., Chou, S. P., Smith, S. M., Ruan, W. J., . . Grant, B. F. (2008). Prevalence, correlates, disability, and comorbidity of DSM-IV Narcissistic Personality Disorder: Results from the Wave 2 National Epidemiologic Survey on Alcohol and Related Conditions. Journal of Clinical Psychiatry, 69, 1033-1045. doi:10.4088/JCP. v69n0701

Torgerson, S., Kringlen, E., \& Cramer, V. (2001). The prevalence of personality disorders in a community sample. Archives of General Psychiatry, 58, 590-596. doi:10.1001/archpsyc.58.6.590

Washburn, J., McMahon, S., King, C., Reinecke, M., \& Silver, C. (2004). Narcissistic features in young adolescents: Relations to aggression and internalizing symptoms. Journal of Youth and Adolescence, 33, 247-260. doi:10.1023/B:JOYO.0000025323.94929.d9

Watson, P. J., Grisham, S. O., Trotter, M. V., \& Biderman, M. D. (1984). Narcissism and empathy: Validity evidence for the Narcissistic Personality Inventory. Journal of Personality Assessment, 45, 159-162. doi:10.1207/s15327752jpa4803_12

West, S., Taylor, A., \& Wu, W. (2012). Model fit and model selection in structural equation modeling. In R. Hoyle (Ed.), Handbook of structural equation modeling (pp. 209-231). New York, NY: Guilford Press.

White, J., Moffitt, T., Caspi, A., Jeglum-Bartusch, D., Needles, D., \& Stouthamer-Loeber, M. (1994). Measuring impulsivity and examining its relationship to delinquency. Journal of Abnormal Psychology, 103, 192-205. doi:10.1037/0021-843X.103.2.192

Wilson, M. S., \& Sibley, C. G. (2011). “Narcissism creep?” Evidence for age-related differences in narcissism in the New Zealand general population. New Zealand Journal of Psychology, 40, 89-95. 